\title{
Correlation of CT Findings and Clinical Characteristics of Pneumocystis Pneumonia in Patients with Acquired Immunodeficiency Syndrome
}

Masayo Kawakami, Masaki Tominaga*, Chiyo Yano, Masaki Okamoto, Masayuki Nakamura, Yuki Sakazaki, Yoshiko Naito, Tomotaka Kawayama and Tomoaki Hoshino

Division of Respirology, Neurology and Rheumatology, Department of Medicine, Kurume University School of Medicine, Japan

*Corresponding author: Masaki Tominaga, Assistant Professor, Division of Respirology, Neurology and Rheumatology, Department of Medicine, Kurume University School of Medicine, Japan, Tel: 81942317560; E-mail: tominaga_masaki@med.kurume-u.ac.jp

Received date: July 30, 2018; Accepted date: August 14, 2018; Published date: August 21, 2018

Copyright: (c) 2018 Kawakami M, et al. This is an open-access article distributed under the terms of the Creative Commons Attribution License, which permits unrestricted use, distribution and reproduction in any medium, provided the original author and source are credited.

\section{Abstract}

Background: Pneumocystis pneumonia (PCP) is the most common opportunistic infection, and it is difficult to diagnose as PCP. The aim of this study was to assess whether CT findings or clinical characteristics contribute to early diagnosis of PCP.

Method: Twenty-six patients with AIDS and PCP received medical treatment at the Kurume University Hospital between 1999 and 2018. None of the patients with AIDS had been diagnosed as HIV positive until the episode of PCP. In this study, the correlation between computed tomography (CT) findings and clinical characteristics were analyzed in patients with AIDS and PCP. The number of patients with PCP is not that high in Japan; therefore, it is difficult to diagnose patients with PCP in the clinic.

Results: This study included 24 men and 2 women, and the mean age was 47.8 years. The mean CD4 cell count was 65.7 cells/ $\mu$ l, HIV-viral load was $680 \times 10^{4}$ copy, $\beta$-D-glucan ( $\left.\beta D G\right)$ level was $234 \mathrm{pg} / \mathrm{ml}$, and mean time till diagnosis was 41.3 days; 14 patients had hypoxemia. Twelve patients had PCP, 10 had cytomegalovirus (CMV) infection, 2 had Cryptococcus infection, 1 had Entamoeba histolytica infection, 1 had non-tuberculous mycobacteria infection, and 1 had Toxoplasma infection. CT images of the patients showed 10 cases with ground-glass opacity (GGO), 13 with consolidation, 1 with small nodules, 2 with a cavity, and 1 with cyst formation. Nine cases revealed peripheral distribution with peripheral sparing, 1 had pleural fluid, and 6 had lymph node enlargement. The mean time till diagnosis and cough were significantly correlated with lymphadenopathy. Patients with consolidation were more likely to be infected with CMV.

Conclusion: GGO, combined with peripheral distribution and peripheral sparing, was the most common CT finding. When consolidation was present in PCP patients as shown in CT images, the patients were more likely to be infected with CMV.

Keywords: Pneumocystis pneumonia; Acquired immunodeficiency syndrome; Computed tomography

\section{Introduction}

Pneumocystis pneumonia (PCP) is a leading result of opportunistic infections in patients with acquired immunodeficiency syndrome (AIDS), and it still results in life-threatening complications. Before antiretroviral therapy, mortality of PCP ranged from $10 \%$ to $30 \%$, with even higher mortality rates of $35 \%$ to $85 \%$ in patients requiring admission to an intensive care unit [1]. When the immunosuppressive state of patients is known, it is not difficult to diagnose them with PCP. But many patients from underserved populations do not receive a diagnosis of HIV infection until they present with PCP. However, neither the immunostatus of all patients nor their sexuality is known. As the number of HIV-infected or AIDS patients is not that high, misdiagnosis of another interstitial lung disease may occur. Dohn et al. [2] presented that patients with second- or third-episode PCP had milder disease and better outcome than patients with first-episode PCP. When patients with PCP are undiagnosed for a long period, PCP leads to a severe condition and can be a fatal disease. In this study, we discuss CT findings of patients with AIDS and PCP and hope that our study results will contribute to the early diagnosis of PCP.

\section{Method}

Twenty-six patients with AIDS and PCP have been registered in the Kurume University Hospital between 1999 and 2018. None of the patients with AIDS had been diagnosed as HIV positive until the episode of PCP. In this study, we analyzed the correlation between CT findings and clinical characteristics of patients with PCP. A diagnosis of PCP was made when one of the following criteria was met: a) detection of Pneumocystis jirovecii by staining (Grocott-Gomori methenamine stain) of a respiratory specimen or b) both positive PCR results for $P$. jirovecii in a respiratory specimen and elevated serum $(1 \rightarrow 3)-\beta$-D-glucan $(\beta D G)$ levels. The cut-off level of $\beta D G$ was set at $31.1 \mathrm{pg} / \mathrm{mL}$ according to a previous report [3]. Cytomegalovirus (CMV) infection was diagnosed using an antigenemia assay (C7HRP). CMV C7HRP positive was recognized if positive cells for pp65 antigen counted over 5 per 50000 cells.

Medical records of all patients were reviewed, and clinical data, courses, and outcomes were evaluated. The symptoms, namely body 
Citation: Kawakami M, Tominaga M, Yano C, Okamoto M, Nakamura M, et al. (2018) Correlation of CT Findings and Clinical Characteristics of Pneumocystis Pneumonia in Patients with Acquired Immunodeficiency Syndrome. Biol Med (Aligarh) 10: 447. doi: $10.4172 / 0974-8369.1000447$

Page 2 of 4

weight loss, cough, dyspnea, fever, and hypoxemia, were chosen as clinical signs. Serum albumin, C-reactive protein (CRP), and $\beta D G$ levels were assessed. In addition, white blood cell (WBC) count was evaluated.

Based on chest high-resolution computed tomography (HRCT), 8 categories were identified (Figure 1): Ground grass opacity (a), consolidation (b), small nodules (c), cavity (d), cyst formation (e), pleural effusion (f), peripheral distribution with peripheral sparing (g) and lymphadenopathy $(\mathrm{h})$.

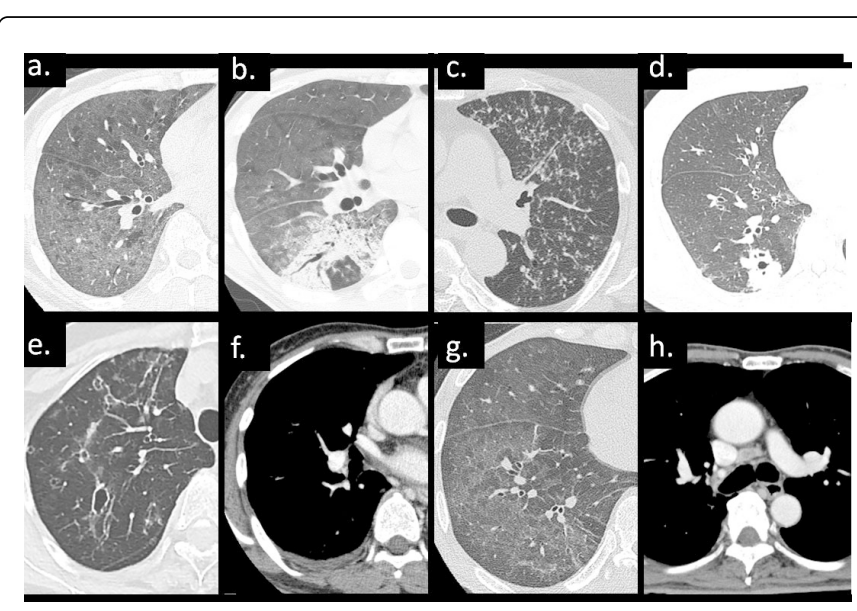

Figure 1: Chest high-resolution computed tomography (HRCT).

\section{Ethical approval}

The study was conducted in accordance with the Good Clinical Practice guidelines and was approved by the ethics committee of Kurume University (No. 18034)

\section{Statistical analysis}

All data analyses were performed using the JMP program version 11.0 (SAS Institute Japan, Tokyo, Japan). Continuous variables are presented as mean \pm standard deviation. Differences in variables between the patients with malignancy and those with AIDS were compared by the non-parametric Mann-Whitney's U-test. Differences in variables between patients with clinical characteristics and CT findings were compared by chi-square test. Differences with $\mathrm{P}$ values of $<0.05$ were considered statistically significant.

\section{Result}

Patient characteristics are summarized in Table 1 . The study group comprised 24 men and 2 women with a mean age of 47.8 years (range: 25-68 years). Seventeen of 41 patients were homosexual, and the mean smoking index (pack-years) was 242. The mean time from symptom onset to diagnosis was 41.3 days. The most common symptom was body weight loss (>10 kg compared to baseline) in $22 / 26$ patients, followed by cough in 11, shortness of breath in 17 , fever in 19, and hypoxemia in 14. Laboratory data showed that mean WBC count was 6592 cells/ $\mu$ l, serum albumin level was $3.1 \mathrm{~g} / \mathrm{dl}$, and CRP level was 3.5 $\mathrm{mg} / \mathrm{dl}$. The mean CD4 cell count was 71 cells/ $\mu$ l, HIV-viral load (VL) was $6.8 \times 10^{6} \mathrm{copy} / \mathrm{ml}$, and $\beta D G$ level was $232 \mathrm{pg} / \mathrm{ml}$. Twelve patients had PCP only, 10 had CMV infection, 2 had Cryptococcus infection, 1 had Entamoeba histolytica infection, 1 had non-tuberculous mycobacteria infection, and 1 had Toxoplasma infection. Trimethoprim-sulfamethoxazole for 21 days was the first-line therapy for patients with PCP, and adjunctive corticosteroids were added for patients with severe hypoxemia.

\begin{tabular}{|c|c|}
\hline Clinical findings & Value \\
\hline Age & $47.8(25-68)$ \\
\hline Gender (male/female) & $24 / 2$ \\
\hline Homosexual & $17 / 24$ \\
\hline Smoking index & $242 \pm 249$ \\
\hline The mean time in diagnosis & $41.3 \pm 72.6$ \\
\hline Body weight loss & $22 / 26$ \\
\hline Cough & $11 / 26$ \\
\hline Dyspnea on effort & $17 / 26$ \\
\hline Fever & $19 / 26$ \\
\hline Hypoxemia & $14 / 26$ \\
\hline WBC $(/ \mu \mathrm{L})$ & $6592 \pm 3864$ \\
\hline Alb (g/dL) & $3.1 \pm 0.7$ \\
\hline CRP (mg/dL) & $3.5 \pm 4.2$ \\
\hline$\beta$-D glucan $(\mathrm{pg} / \mathrm{mL})$ & $234 \pm 271$ \\
\hline CD4 cell count $(/ \mu \mathrm{L})$ & $65.7 \pm 74.2$ \\
\hline HIV-VL (× $\left.10^{4} \mathrm{copy} / \mu \mathrm{l}\right)$ & $680 \pm 2933$ \\
\hline Cytomegarovirus antigenemia & $12 / 26$ \\
\hline
\end{tabular}

Table 1: Patient characteristics with PCP.

CT images showed that 10 patients had GGO, 13 had consolidation, 1 had small nodular shadow, 2 had cavitary lesion, and 1 had cyst formation. Nine cases showed peripheral distribution with peripheral sparing, 1 case had pleural fluid, and 6 cases had lymphadenopathy (Table 2). All of the cases with consolidation were positive for GGO. The mean time till diagnosis and lymphadenopathy, cough and lymphadenopathy, and consolidation and cough were significant different (Table 3). There was no statistically significant association between GGO and CMV C7-HRP, but PCP patients with consolidation were more likely to be infected with CMV.

Next, GGO and consolidation cases were compared because the number of cases was high. The number of patients with dyspnea on exertion in cases with consolidation was significantly higher than in patients with GGO (Table 4).

\begin{tabular}{|l|l|}
\hline \multicolumn{1}{|c|}{ Characteristic CT findings } & \multicolumn{1}{|c|}{ Number of cases $(\%)$} \\
\hline Ground grass opacity & $23 / 26(88 \%)$ \\
\hline Consolidation & $12 / 26(46 \%)$ \\
\hline Small nodules & $1 / 26(4 \%)$ \\
\hline Cavity & $2 / 26(8 \%)$ \\
\hline
\end{tabular}


Citation: Kawakami M, Tominaga M, Yano C, Okamoto M, Nakamura M, et al. (2018) Correlation of CT Findings and Clinical Characteristics of Pneumocystis Pneumonia in Patients with Acquired Immunodeficiency Syndrome. Biol Med (Aligarh) 10: 447. doi: $10.4172 / 0974-8369.1000447$

Page 3 of 4

\begin{tabular}{|l|l|}
\hline Cyst formation & $1 / 26(4 \%)$ \\
\hline Peripheral distribution with peripheral sparing & $9 / 26(35 \%)$ \\
\hline Pleural effusion & $1 / 26(4 \%)$ \\
\hline Lymphadenopathy & $6 / 26(23 \%)$ \\
\hline
\end{tabular}

Table 2: Characteristic CT findings of PCP.

\begin{tabular}{|c|c|c|c|c|}
\hline & GGO & Consolidation & $\begin{array}{c}\text { Spare } \\
\text { periphery }\end{array}$ & Lymphadenopathy \\
\hline Age & $0.717 \dagger$ & $0.442 \dagger$ & $0.983 \dagger$ & $0.820 \dagger$ \\
\hline $\begin{array}{l}\text { Smoking } \\
\text { index }\end{array}$ & $0.323 \dagger$ & $0.481 \dagger$ & $0.537 \dagger$ & $0.314 \dagger$ \\
\hline $\begin{array}{l}\text { The mean } \\
\text { time in } \\
\text { diagnosis }\end{array}$ & $0.165^{*}$ & $0.149^{*}$ & $0.837^{*}$ & $0.030^{*}$ \\
\hline $\begin{array}{l}\text { Body weight } \\
\text { loss }\end{array}$ & $0.735^{*}$ & $0.356^{*}$ & $0.114^{*}$ & $0.165^{\star}$ \\
\hline Cough & $0.599^{*}$ & $0.462^{*}$ & $0.500^{*}$ & $0.017^{*}$ \\
\hline $\begin{array}{l}\text { Dyspnea on } \\
\text { exertion }\end{array}$ & $0.320^{*}$ & $0.009^{*}$ & $0.920^{*}$ & $0.366^{*}$ \\
\hline Fever & $0.353^{*}$ & $0.275^{*}$ & $0.694^{*}$ & $0.686^{*}$ \\
\hline Hypoxemia & $0.098^{*}$ & $0.716^{*}$ & $0.340^{*}$ & $0.829^{*}$ \\
\hline WBC $(/ \mu \mathrm{L})$ & $0.451 \dagger$ & $0.155 \dagger$ & $0.668 \dagger$ & $0.548 \dagger$ \\
\hline Alb (g/dL) & $0.507 \dagger$ & $0.085 \dagger$ & $0.553 \dagger$ & $0.851 \dagger$ \\
\hline $\mathrm{CRP}(\mathrm{mg} / \mathrm{dL})$ & $0.528 \dagger$ & $0.829+$ & $0.612 \dagger$ & $0.459+$ \\
\hline $\begin{array}{l}\beta-D \text { glucan } \\
(\mathrm{pg} / \mathrm{mL})\end{array}$ & $0.768 \dagger$ & $0.391 \dagger$ & $0.818 \dagger$ & $0.315 \dagger$ \\
\hline CMV C7HRP & $0.189^{*}$ & $0.064^{*}$ & $0.915^{*}$ & $0.356^{*}$ \\
\hline 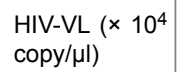 & $0.391 \dagger$ & $0.491 \dagger$ & $0.410 \dagger$ & $0.271 \dagger$ \\
\hline
\end{tabular}

Note: GGO: Ground Grass Opacity; †: Mann-Whitney's U-test; *: chi-square test

Table 3: Clinical characteristics and CT findings.

\begin{tabular}{|l|l|l|l|}
\hline & \multicolumn{1}{|c|}{ GGO } & Consolidation & P value \\
\hline Age & 46.8 & 45.8 & 0.85 \\
\hline Smoking index & $184 \pm 212$ & $280 \pm 278$ & 0.37 \\
\hline The mean time in diagnosis & $5 / 11$ & $2 / 12$ & 0.13 \\
\hline Body weight loss & $9 / 11$ & $11 / 12$ & 0.48 \\
\hline Cough & $4 / 11$ & $6 / 12$ & 0.51 \\
\hline Dyspnea on exertion & $6 / 11$ & $11 / 12$ & $\mathbf{0 . 0 4}$ \\
\hline Fever & $7 / 11$ & $10 / 12$ & 0.28 \\
\hline Hypoxemia & $8 / 11$ & $6 / 12$ & 0.27 \\
\hline WBC $(/ \mu \mathrm{L})$ & $5908 \pm 2127$ & $7766 \pm 5029$ & 0.27 \\
\hline
\end{tabular}

\begin{tabular}{|l|l|l|l|}
\hline Alb $(\mathrm{g} / \mathrm{dL})$ & $3.2 \pm 0.7$ & $2.8 \pm 0.5$ & 0.22 \\
\hline CRP $(\mathrm{mg} / \mathrm{dL})$ & $4.1 \pm 4.5$ & $3.7 \pm 4.3$ & 0.82 \\
\hline$\beta$-D glucan $(\mathrm{pg} / \mathrm{mL})$ & $252 \pm 242$ & $183 \pm 225$ & 0.49 \\
\hline CMV C7HRP & $2 / 11$ & $6 / 12$ & 0.11 \\
\hline HIV-VL $\left(\times 10^{4} \mathrm{copy} / \mathrm{\mu l}\right)$ & $1389 \pm 4514$ & $84 \pm 158$ & 0.33 \\
\hline CD4 cell count $(/ \mu \mathrm{L})$ & $50.8 \pm 65.3$ & $76.8 \pm 83.3$ & 0.42 \\
\hline Note: GGO: Ground Grass Opacity & & \\
\hline
\end{tabular}

Table 4: Comparison between ground grass opacity and consolidation.

\section{Discussion}

The primary objective of the present study was to identify CT abnormalities to diagnose PCP in patients as early as possible. Furthermore, radiological manifestations and clinical characteristics were compared to identify the severity or prognosis of patients with AIDS and PCP.

PCP is caused by $P$. jirovecii and is a common source of opportunistic infection affecting immunosuppressed patients. Approximately $90 \%$ of cases of PCP occurred in AIDS patients with CD4 cell counts of $<200$ cells $/ \mathrm{mm}^{3}$. The most common manifestations of PCP are subacute-to-mild onset of progressive dyspnea, fever, and cough that worsen within days to weeks or sometimes months [4]. Some studies have shown that $\mathrm{CT}$ is more sensitive for the diagnosis of PCP, and the most common CT finding in these patients is diffuse GGO $[5,6]$. Consolidation, nodules, cyst formation, pleural effusion, and spontaneous pneumothorax may develop, but these findings are thought to be present in an advanced phase of PCP [6].

In this study, the frequency of body weight loss, fever, and dyspnea was $85 \%, 73 \%$, and $65 \%$, respectively. The median duration from onset of symptoms till diagnosis was 41 days, which was not long compared with that found in previous reports [4]. A possible explanation is that patients can easily access the hospital, and doctors are likely to perform chest CT when they suspect an interstitial lung disorder. Furthermore, HIV infection and opportunistic infections, such as PCP, are well recognized in the homosexual community in the past 20 years because patients tend to visit the hospital in the early phase of PCP.

Table 5 summarizes the CT findings in previous reports and our study [4-10]. Our results are in agreement with those of previous studies that analyzed CT presentation of PCP in patients with AIDS. The most common CT findings were the presence of bilateral GGO distributed in a diffuse pattern and sparing of the peripheral subpleural lung. Several reports showed that PCP may also be associated with upper lobes predominance, but this finding was less common in our patients [11]. Interestingly, the frequency of consolidation in our study was greater than that in previous reports, and there were no upper lobe dominant distribution cases in our study. A few studies have reported that upper lobe distribution may be associated with aerosolized pentamidine prophylaxis [11].

In general, consolidation superimposed on GGO is considered to reveal a more advanced phase [6]. There was no correlation of GGO and consolidation with CD4 cell counts, HIV-VL, or disease severity, such as hypoxemia. Other bacterial infections in patients with GGO and consolidation were ruled out by using respiratory sample culture. Cases with consolidation, however, tended to be positive for CMV C7- 
Citation: Kawakami M, Tominaga M, Yano C, Okamoto M, Nakamura M, et al. (2018) Correlation of CT Findings and Clinical Characteristics of Pneumocystis Pneumonia in Patients with Acquired Immunodeficiency Syndrome. Biol Med (Aligarh) 10: 447. doi: $10.4172 / 0974-8369.1000447$

Page 4 of 4

HRP. Definitive diagnosis of CMV pneumonia is determined based on a combination of symptoms and signs of pulmonary disease and detection of $\mathrm{CMV}$ in bronchoalveolar lavage fluid or lung tissue samples by virus isolation, histopathologic testing, immunohistochemical analysis, or in in situ hybridization. Studies on CT findings of CMV infections have reported a combination of GGO, consolidation, nodules, poorly defined small centrilobular nodules, bronchial dilatation, and thickened interlobular septa $[10,11]$. In this study, no diagnosis of CMV pneumonia was made because lung biopsy was not performed. Therefore, consolidation may be a sign of CMV pneumonia or organizing pneumonia accompanied with acute alveolar damage by PCP. Tasaka et al. revealed that lung consolidation is more common in patients without HIV infection and tends to develop more rapidly, reflecting pulmonary damage by the host immune response [9]. Thus, CMV infection must be suspected when consolidation with GGO is detected in patients with AIDS and PCP.

\begin{tabular}{|c|c|c|c|c|c|c|c|c|}
\hline & Our cases & Chaffey & Kuhlman & Hartman & Fujii & Tasaka & Kanne & Ebner \\
\hline Year & 2018 & 1990 & 1990 & 1993 & 2007 & 2010 & 2012 & 2016 \\
\hline Number & 26 & 64 & 39 & 24 & 32 & 17 & 32 & 16 \\
\hline GGO (\%) & 88 & 65.6 & 26 & 92 & 53 & 100 & 53 & 69 \\
\hline Consolidation (\%) & 46 & 25 & - & 38 & 38 & 5 & - & 31.3 \\
\hline Small nodule (\%) & 4 & - & - & 25 & - & 5 & - & 87.5 \\
\hline Nodule (\%) & 12 & - & 18 & 25 & 9 & - & - & - \\
\hline Cavitation (\%) & 8 & - & 8 & - & 6 & - & - & - \\
\hline Cyst (\%) & 4 & 7.8 & 38 & 33 & 21 & 18 & - & 31.3 \\
\hline Linear/reticular (\%) & 0 & 45.3 & 18 & 17 & 18 & 18 & - & 81.3 \\
\hline Peripheral spare (\%) & 35 & - & - & - & 41 & 59 & 41 & 50 \\
\hline Effusion (\%) & 4 & 9.5 & 18 & 17 & - & - & - & 12.5 \\
\hline Pneumothorax (\%) & 0 & 3.1 & 13 & 17 & - & - & - & 6.3 \\
\hline Lymphadenopathy (\%) & 23 & 7.8 & 18 & 25 & - & - & - & 43.8 \\
\hline
\end{tabular}

Table 5: Characteristics of CT findings with our patients and previous reports [4-10].

\section{Conclusion}

CT is a highly sensitive method, and it may also be helpful in the differential diagnosis of PCP in patients with AIDS. The accuracy of the diagnosis based on CT findings was high; therefore, the characteristics of PCP should identified using CT images.

\section{References}

1. Fei MW, Kim EJ, Sant CA, Jarlsberg LG, Davis JL, et al. (2009) Predicting mortality from HIV-associated Pneumocystis pneumonia at illness presentation: an observational cohort study. Thorax 64: 1070-1076.

2. Dohn MN, Baughman RP, Vigdorth EM, Frame DL (1992) Equal survival rates for first, second, and third episodes of Pneumocystis carinii pneumonia in patients with the acquired immunodeficiency syndrome. Arch Intern Med 152: 2465-2470.

3. Tasaka S, Hasegawa N, Kobayashi S, Yamada W, Nishimura T, et al. (2007) Serum indicators for the diagnosis of Pneumocystis pneumonia. Chest 131: 1173-1180.

4. Fujii T, Nakamura T, Iwamoto A (2007) Pneumocystis pneumonia in patients with HIV infection: clinical manifestations, laboratory findings, and radiological features. J Infect Chemother 13: 1-7.

5. Hartman TE, Primack SL, Müller NL, Staples CA (1994) Diagnosis of thoracic complications in AIDS: accuracy of CT. AJR Am J Roentgenol 162: 547-553.
6. Kanne JP, Yandow DR, Meyer CA (2012) Pneumocystis jiroveci pneumonia: high-resolution CT findings in patients with and without HIV infection. Am J Roentgenol 98: 555-561.

7. Chaffey MH, Klein JS, Gamsu G, Blanc P, Golden JA (1990) Radiographic distribution of Pneumocystis carinii pneumonia in patients with AIDS treated with prophylactic inhaled pentamidine. Radiology 175: 715-719.

8. Kuhlman JE, Kavuru M, Fishman EK, Siegelman SS (1990) Pneumocystis carinii pneumonia: spectrum of parenchymal CT findings. Radiology 175: 711-714.

9. Tasaka S, Tokuda H, Sakai F, Fujii T, Tateda K, et al. (2010) Comparison of clinical and radiological features of pneumocystis pneumonia between malignancy cases and acquired immunodeficiency syndrome cases: a multicenter study. Intern Med 49: 273-281.

10. Ebner L, Walti LN, Rauch A, Furrer H, Cusini A, et al. (2016) Clinical course, radiological manifestations, and outcome of pneumocystis jirovecii pneumonia in HIV patients and renal transplant recipients. PLoS One 11: e0164320.

11. Hardak E, Brook O, Yigla M (2010) Radiological features of Pneumocystis jirovecii Pneumonia in immunocompromised patients with and without AIDS. Lung 188: 159-163. 